\title{
I. Chemical examination of the fire damp from the coal mines near Newcastle
}

\section{Edward Turner M.D. F.R.S. London and Edinb. V.P.G.S.}

To cite this article: Edward Turner M.D. F.R.S. London and Edinb. V.P.G.S. (1839) I. Chemical examination of the fire damp from the coal mines near Newcastle, Philosophical Magazine Series 3, 14:85, 1-10, DOI: 10.1080/14786443908649649

To link to this article: http://dx.doi.org/10.1080/14786443908649649

册 Published online: 01 Jun 2009.

Submit your article to this journal $\lceil\pi$

Џ Article views: 2

Q View related articles $\square$ 


\author{
A N D \\ JOURNAL OF SCIENCE.
}

[THIRD SERIES.]

$J A \dot{N} U A R Y 1839$.

I. Chemical Examination of the Fire Damp from the Coal Mines near Nerwcastle. By [the late] Edward Turner, M.D., F.R.S. London and Edinb., V.P.G.S., Professor of Chemistry in the University of London.*

THE gases subjected to examination were collected under the direction of Mr. Hutton, by emptying Winchesterquart bottles filled with water, at the spot where it was designed to collect the gas, and then inserting a well-greased ground-glass stopper, which was afterwards secured in position by cement, and a covering of bladder. About half an ounce of water was left in each bottle, and the bottles were sent to me packed in boxes in an inverted position. In most instances, when the stoppers were withdrawn in the pneumatic trough, a portion of water instantly rushed in, showing both that the means of securing the gases had proved effectual, and

[* From the Transactions of the Natural History Society of Northumberland, Durham, and Newcastle-upon-Tyne, vol. ii. Part ji.] From the period of its institution the Natural History Society had directed particular attention to the evolution of gas in coal mines, and many papers had been read from time to time, when the feelings of the public were most painfully excited to the subject by the awful calamity at Wallsend Colliery, on the 18th of June, 1835, described by Mr. Buddle in the preceding paper [in the Society's 'Transactions]. At this time an inquiry was in progress before a Committee of the House of Commons, which soon after published its report. It was given in evidence before this Committee, that both free hydrogen and olefiant gas occur in the atmosphere of some coal mines ; this, as striking at once at the efficacy of the Davy lamp in preventing explosions, seemed to be a matter requiring immediate attention in a district where that instrument is so extensively used, and where its safety is so entirely relied upon. With this view, immediately after the publication of the Parliamentary Report, the Natural History Society deternined to institute such an inquiry, and Mr. Hutton was directed to communi.

Phil. Mag. S. 3. Vol. 14. No.85. Jan. 1839. B 
that the gases within the mine were in a more rare state than in my laboratory.

As one of the principal objects of the inquiry was to determine in how far the gas of different mines varied in chemical constitution, it was material to multiply as much as possible the samples of gas submitted to examination. 'The number of samples actually received and examined by me amounted to twelve. The result of this analysis will be given in a tabular form at the close of this communication. The general conclusion deducible from them is, that the essential and sole inflammable material of fire-damp, as formerly found by Dr. Henry and Sir Humphry Davy, is the light carburetted hy-

cate with the committee of the coal trade to ask their valuable co-operation and assistance; for this purpose he addressed the following letter to Robert William Brandling, Esq., the chairman.

Copy.

"Newcastle, January 9 th, 1836 .

"Sir,-I beg leave respectfully to state, that at the last meeting of the Natural History Society, after the reading of a parer on the gas of mines, it was resolved that the Society should do all in its power to promote an investigation into the nature of the gas evolved in our different collieries, for the purpose of ascertaining if any other, and what gas, occurs besides the common carburetted hydrogen, it having been stated in evidence before the late Parliamentary Committee, that free hydrogen and olefiant gas are both to be found in the mines of Wales. I was directed by the Society to bring the matter before the Committee of the Coal Trade, and request their valuable co-operation and assistance in obtaining an extensive analysis by one of the first chemists of the day, so as at once to set at rest the question as to the nature of coal gas spontaneously evolved in this district. Dr. Turner was named as the person best fitted for the task, not only from his great skill as an analyst, but from his extensive knowledge as a geologist, and the attention he has paid to the chemistry of niture, so to speak.

"This investigation will not be an expensive one, and it was thought, from the deep importance of the question as connected with the safetylamp, that the Coal Trade would have no objections to join the Society in the cost. The Society are anxious that this investigation should be made speedily, as they are about going to press with a conclusion of the second volume of their Transactions, where they would wish this to appear as forming an appropriate Appendix to the many valuable papers in the work connected wich our local geology and mining. If the Committee of the Coal Trade agree to give their assistance in this matter, the Society will furnish them with any number of copies of the results of the investigation they may require; and, individually, I most respectfully beg to offer my personal services in collecting the specimens of gas, and making such arrangements as will secure their conveyance to London unadulterated.

\section{"To Robert William Brandling, Esq."}

"I have the honour to be, \&c. \&c.

"Willitam Hutton, Secretary.

The Coal Trade Committee immediately adopted the suggestion, and appointed John Buddle, George Johnson, and Nicholas Wood, Esqre., to make the necessary arrangements for collecting the specimens of gas. 
drogen, or marsh gas of chemists, which issues in a state of purity from coal, wholly free from admixture with hydrogen, carbonic oxide, or olefiant gases, and but rarely containing a trace of carbonic acid gas*. The sole difference in the explosive gas of different mines must hence be referred to the degree of admixture with air. If diluted with nineteen or twenty times its volume of air, the mixture does not detonate or take fire at all ; on diminishing the proportion of air below this term the mixture becomes inflammable, and on the approach of a lighted candle, a pale blue flame appears, which passes slowly through the mixture when the air is in large excess; rapidly when the ratio is favourably adjusted for combustion. The most explosive mixture, as Davy correctly states in his "Essay on Flamet," is formed of one measure of pure fire-damp, and about seven measures of air. Such mixture, unlike an explosive mixture made with air and hydrogen or carbonic oxide gas, is not kindled by incandescent solid matter, such as a mass of hot iron; but it burns rashly [rapidly?] in contact with flame, and detonates readily with the electric spark. As the proportion of pure fire-damp rises above a sixth, the mixture burns less and less readily, and the tint of the flame changes at the same time from blue to yellow or brown. The phænomena receive a ready explanation from. the well-known principles established by Davy.

The analysis of fire-damp was performed by detonation with oxygen gas over mercury. In successful analysis with all the gases, the diminution in volume subsequent on detonation with the electric spark, and due to gaseous matter condensed as water, was precisely twice the volume of carbonic acid gas which was generated, and equal to the oxygen gas which disappeared. The volume of carbonic acid gas sometimes fell short of half the diminution due to production of

* Extract of a letter from Major Emmett, Royal Engineer, to Mr. Hutton, dated Hull, 19th February, 1836.

"I send you the following extracts from a letter from Dr. Dalton of the 13th. As regards Wallsend Pit, they are important, and to me conclusive. I sent him three bottles Mr. Buddle had collected for me about three months ago, also one of water from the old working at Gateshead Park Pit, forwarded to me by Mr. Wood. Respecting the Wallsend gas be says : 'I received your letter and bottles of gas safely, and soon after opened the bottles under water. The air in each bottle was very much alike. It was constituted of some two or three per cent. of carbonic acid, about one tenth common air rather short of oxygen, and the rest, about eighty-five per cent., was pure carburetted hydrogen, or pond gas, without a trace of either pure hydrogen or olefiant gas.' Respecting the Gateshead water he says, "The bottle of water from the old waste I also examined; it contained about one per cent. of soluble matter, chiefly common salt, with some carbonic acid, sulphurous acid, sulphuretted hydrogen and lime." "

[t See Phil. Mag. First Series, vol. xlxvi. p. 448.] 
water, but this only took place when the combustion was incomplete. Sometimes the gaseous mixture, after detonation, was more or less obscured by a deposit of carbonaceous matter, and in such instances, as already remarked by Dr. Henry, there is always a deficiency of carbonic acid gas, which deficiency is less considerable the more completely the mixture at the moment of detonation approximates to perfect transparency. I have occasionally observed this cloud, even when ample oxygen for complete combustion was present; but with a decided excess of oxygen it generally does not occur at all, or at most in so slight a degree as not to be appreciable. To show the course of the inquiry, I quote three analyses, in the first of which an error, from deposited carbon, is apparent.

I. Analysis of fire-damp from Jarrow Colliery, rohich issued from a seam of coal eleven fathoms below the Bensham seam.

Specific gravity as found by weighing the gas $=0.6209$. Tested by nitrous gas it was found in one experiment to contain 2.25 per cent. of oxygen, and in a second 2.1 per cent., indicating as a mean $2 \cdot 2$ per cent. of oxygen, equivalent to 11 per cent. of air. This gas, which was quite free from carbonic acid gas, may be considered as a mixture of 89 measures of real marsh gas with 11 measures of air. A gas so constituted, and assuming 0.5595 as the specific gravity of marsh gas, should have a specific gravity 0.6079 ; for 0.5595 $+0.89+0.11=0.6079$. Of this gas 12.3 measures, containing 0.3 of oxygen and 11 of real marsh gas, were fired with $32 \cdot 7$ measures of a sample of oxygen gas, which contained 31 of real oxygen gas:-

Loss due to condensed water ..................... $=22.3$

Carbonic acid gas generated and absorbed by potassa ...................................... $=9 \cdot 4$

Residual oxygen, determined by firing with hydrogen gas .................................. $=10.5$

Deducting $10.5+9 \cdot 4$, the oxygen above accounted for, from $31 \cdot 3$, the whole oxygen gas originally present, there remain, as Oxygen gas which went to the production of water $\ldots=1 \mathrm{i} \cdot 4$

II. Analysis of a gas from the Bensham coal seam, Jarrow Colliery, collected from a blower, which caused the accident in 1826.

Specific gravity actually observed $=0.6381$.

This gas was quite free from carbonic acid gas. In two 
trials with nitrous gas, it was found to contain 3.7 per cent. of oxygen, equivalent to 18.5 of air. A gaseous mixture of 18.5 air, and 81.5 real marsh gas, should have a specific gravity of 0.641 , since $0.5595+0.815+0.185=0.641$.

Of this gas 13.5 measures, inferred from the foregoing premises to contain 0.5 of oxygen and 11 of real marsh gas, were fired with 30 measures of oxygen, which contained $28 \cdot 8$ of real oxygen gas.

Loss of volume due to production of water $=22.8$

Carbonic acid gas generated ................. $=11 \cdot 2$

Residual oxygen ............................ $=6 \cdot 4$

Deducting $17^{\circ} 6$ from $29 \cdot 3$ there rémain, as Oxygen gas which went to the production of water .............................. $=11 \cdot 7$

III. Analysis of a gas from the Eppleton Jane Pit, Hutton Seam, Hetton Colliery, collected at a depth of 175 fathoms beloro the surface.

Specific gravity actually observed ......... $=0.78$.

This gas was quite free from carbonic acid. Two experiments with nitrous gas agreed in indicating the presence of 4.6 per cent. of oxygen, equivalent to 23 measures of air. Analysis indicated the presence of 50 per cent. of real marsh gas, leaving 27 per cent. as nitrogen, independently of that already considered as atmospheric air.

Of this gas 11 measures, containing 0.5 of oxygen, were fired with 28 of oxygen gas, which contained 26.9 of real oxygen.

Loss of volume due to formation of water... $=10.5$

Carbonic acid gas genernted ................. $=5.5$

Residual oxygen ............................ $=16^{\circ} 4$

Deducting $5 \cdot 5+16 \cdot 4=21 \cdot 9$ from $27 \cdot 4$ there remain, as Oxygen gas which went to the formation of water ........................ $=5.5$

A gaseous mixture, consisting of 50 measures of real marsh gas, 23 of air, and 27 of nitrogen, should have a specific gravity of 0.7724 , since $0.5595+0.5+0.23+0.9727+0.27$ $=0.7724$.

The first of the foregoing analyses supplies an instance where the loss of carbon was decisive. In the second and third, as in the whole series of successful analyses, the carbonic acid gas may be taken as exactly equal to half the condensation due to the formation of water, and as containing half the oxygen which was required for complete combustion. The quantity of marsh gas present was equal to half the oxygen required for its complete combustion, to half the condensation due to generated water, and to the volume of car- 
bonic acid gas which was produced, As this was a uniform result in all the samples, it is manifest that the constitution of the inflammable principle of fire-damp is identical with that of marsh gas or light carburetted hydrogen. The proportions of carbon and hydrogen indicated by analysis, sufficiently demonstrate the absence of such gases as hydrogen, carbonic oxide, and olefiant gas. Their absence, however, was proved by other methods. A portion of fire-damp was mixed in a tube with chlorine of known purity, and the mixture kept for a quarter of an hour in a dark place, when the chlorine was absorbed by milk of lime; the original quantity of fire-damp was always recovered, except a slight loss due to the mere washing to absorb the chlorine. The absence of olefiant and carbonic oxide gases was also proved by means of spongy platinum. In 1824, soon after the curious action of spongy platinum in causing the combination of oxygen and hydrogen gases was made known by Dobereiner, both Dr. Henry and myself pointed out the obstacles to that action, occasioned by carbonic oxide, olefiant gas, and some other gases*. (Philosophical Transactions, and Edinburgh Philosophical Journal for 1824.) And Dr. Henry at the same time showed that marsh gas differs remarkably in this respect from carbonic oxide and olefiant gases, as it offers scarcely any impediment to the action of platinum. Agreeably to those researches, it follows that, if fire-damp contained merely marsh gas, oxygen, and nitrogen, spongy platinum introduced at common temperatures, or even heated to $300^{\circ}$ Fahr., would not produce any sensible effect; and that if a small quantity of an explosive mixture $\downarrow$ made with one measure of oxygen, and two measures of hydrogen gases, were added to the firedamp, spongy platinum should cause a production of water corresponding to the quantity of explosive mixture so introduced, without the production of any carbonic acid. But if carbonic oxide or olefiant gas were present, then cold spongy platinum would not act at all, a small proportion of explosive mixture being employed; and if the action were forced by using hot spongy platinum, or by the free introduction of explosive mixture, then would carbonic acid as well as water be generated.

To apply these facts to the case in point, some very active platinum balls, of the size of peas, were made from a mixture of pipe-clay, spongy platinum, and the yellow ammoniacal chloride of platinum, the materials being mixed with water so as

[* Dr. Henry's paper on this subject, from the Philosophical Transactions, will be found in Phil. Mag. First Series, vol. lxv. p. 269,-Eort.]

+ By the expression "explosive mixture," I hereafter mean a mixture made with one measure of oxygen and two measures of hydrogen gases. 
to form a plastic mass, which, after receiving the required size and form, was gently dried, and ignited for an instant before the blow-pipe*, and were introduced into the gaseous mixture over mercury, sometimes cold and at others warm, ten or twenty seconds after incandescence. Their action on all the samples of fire-damp was precisely of the same character with firedamp, oxygen being previously added or not; the platinum balls, whether cold or warm, were completely inactive. On adding some explosive mixture to the fire-damp, the platinum balls acted readily to their full extent. To give some instances.-

I. With fire-damp from the yard coal seam, Burraton Colliery, the specific gravity of which was $0 \cdot 600$.

With 46.5 measures of this gas, and 12.5 of explosive mixture, a platinum ball, nearly cold, caused in ten minutes a loss of volume equal to 12 measures.

In a second trial the loss in ten minutes was 13.6 in a mixture of 49 measures of fire-damp, and $14 \cdot 1$ of explosive mixture.

II. With fire-damp from the Bensham coal seam, Wallsend Colbiery, the specific gravity of rohich roas 0.6024.

In a mixture made with 34.3 measures of fire-damp, and 13.1 of explosive mixture, a platinum ball introduced warm, caused in six minutes a loss of volume equal to $12 \cdot 4$ measures.

With 43.5 measures of the same gas, and 22.9 of explosive mixture, the loss in eight minutes was $21 \cdot 7$, the platinum ball being introduced warm.

With 55 measures of the same gas, and 7 of explosive mixture, a cold platinum ball caused a loss of 6.3 in six minutes.

The action was equally rapid with the other gases; nearly the whole explosive mixture disappearing within the first or second minutes after the introduction of a platinum ball, whether warm or cold. In no instance did barytic water, subsequently admitted, detect in the residue a trace of carbonic acid gas.

When to any specimen of fire-damp hydrogen was added, the action of platinum always revealed the presence of air. When the quantity of air was small, the action of platinum was of course slow; nor did it in that case indicate with fidelity the quantity of air present, a portion of oxygen not uniting with hydrogen. Thus in the fire-damp from the yard coal seam, Burraton Colliery, nitrous gas indicated the presence of 6.2 per cent. of air, and platinum only 3.3 per cent. In the gas from the Bensham Seam, Wallsend Colliery, ni-

* Before use the little balls were always ignited. 


\section{The late Dr. Turner's Chemical Examination of the}

trous gas indicated the presence of 9 per cent. of air; whereas platinum detected only 5 per cent. in one trial, 8.5 per cent. in a second, and 6 per cent. in a third. A certain degree of impediment to the action of platinum by marsh gas is thus rendered apparent. But when the fire-damp was freely mixed with air, then after the hydrogen gas platinum acted freely; and I have found under such circumstances the indications from platinum to coincide with those from nitrous gas. Thus in fire-damp from the low-main coal seam, Killingworth Colliery, of specific gravity 0.8226 , platinum and hydrogen indicated 9.4 per cent. of oxygen, equivalent to 46.5 of air; and in two experiments with nitrous gas precisely the same result was obtained. A ball of platinum may hence be applied to determine the air in fire-damp, even when its quantity is small, by first diluting the gas with a known quantity of air, or enlivening the action of the platinum by adding some explosive mixture.

To those chemists who chance to be practically conversant with the action of platinum on gaseous mixtures, the evidence above adduced as to the freedom of fire-damp from hydrogen, carbonic oxide, olefiant gas, sulphuretted hydrogen, and similar inflammable gases, will, I doubt not, be quite satisfactory. To myself they do not leave the shadow of a doubt on the question. Those who are not familiar with such researches, may be warned that, in repeating my experiments, they will certainly fail of witnessing the same phænomena, unless they are very scrupulous in having pure gases, and in employing platinum balls with their full energy. The influence of platinum on gases is modified by such very slight circumstances, that a small matter will cause a ball to be wholly inert which would otherwise have acted with effect.

In applying nitrous gas to determine the quantity of oxygen in fire-damp, I employed the method of Dr. Dalton, as described in Dr. Henry's Elements of Chemistry. A measured quantity of fire-damp was added to the nitrous gas contained in a graduated tube half an inch wide, and the gases were allowed to act on each other over water, without agitation. The diminution of volume had attained its maximum in five or six minutes, and in general much sooner. Of the total loss, $\frac{1}{2} \frac{0}{7}$ ths were taken as oxygen. This method is not in all cases rigidly correct, but its indications were sufficiently exact for my purpose, controlled as they were by the action of platinum, by the analysis of the gas by detonation with oxygen, and by the specific gravity of the gases. Before relying at all on this method, however, I applied it in the analysis of gaseous mixtures containing known quantities of oxygen gas. On ap- 
plying it to the analysis of atmospheric air it indicated $20^{\circ} 4$ per cent. of oxygen. On agitating the air and nitrous gas, just after admitting them into the same tube, the diminution in volume was excessive. In a specimen of nitrogen gas, to which so much air was admitted that the whole mixture contained 3 per cent. of oxygen, nitrous gas indicated 3.3 per cent. of oxygen in one experiment, and 3.2 in a second. With nitrogen, which contained 3.6 per cent. of oxygen, nitrous gas indicated $4 \cdot 4$ in one trial, and in a second $4 \cdot 1$ per cent of oxygen. In nitrogen gas, with $4 \cdot 7$ per cent. of oxygen, nitrous gas indicated 4.7 per cent. in one trial, and 5.2 in a second. In nitrogen containing $7 \cdot 3$ per cent. of oxygen gas, nitrous gas indicated $7 \cdot 4$ in the first experiment, and $8 \cdot 4$ in the second. In the last case a large excess of nitrous gas was employed. In nitrogen gas in one experiment, and 11.5 in a second*. In this last case also nitrous gas was used in large excess.

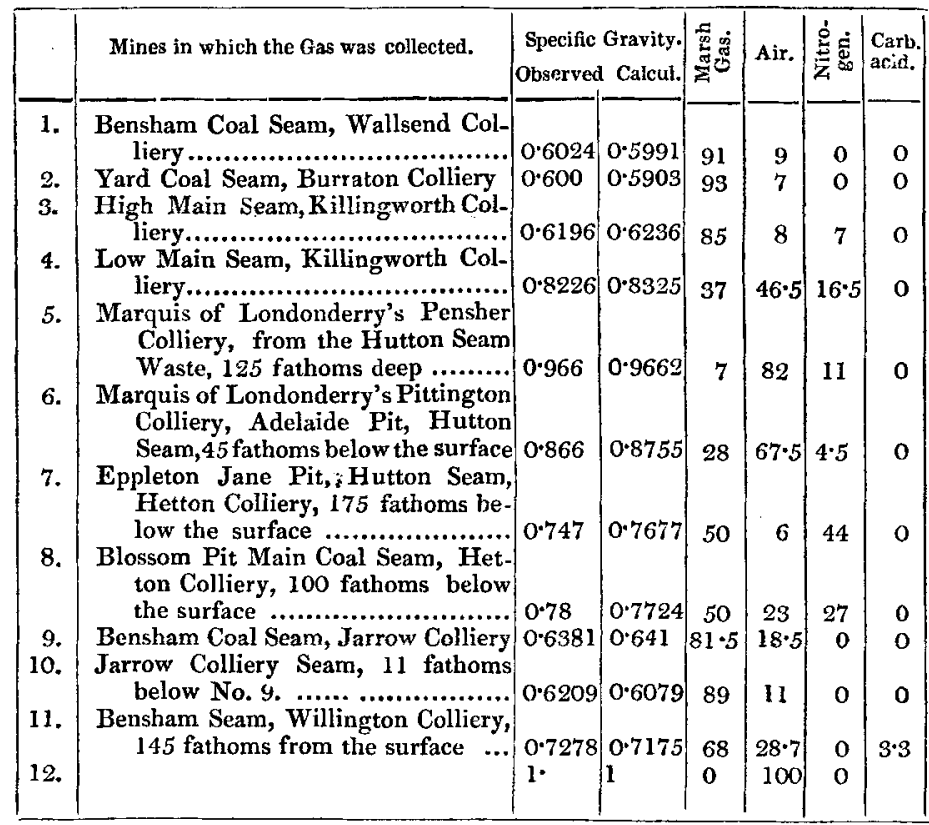

In these experiments the error is very uniformly such, that more oxygen was indicated than was actually present. The causes of error appear to be especially twofold,-agitation, and a large excess of nitrous gas. By permitting the action to ensue tranquilly, and avoiding much excess from nitrous gas, the indications in my trials were uniform, and very nearly true. Applying the same method to fire-damp, I found that

[* There appears to be some omission here. Ebrr. Phrc. MaG.] 
in two or more trials with the same gas the indications hardly ever differed so much as 1 per cent. of oxygen; and in gene$\mathrm{ral}$, as in several instances already given, the coincidence in different experiments was exact. Having now mentioned all that appears necessary to elucidate the chemical nature of the different samples of fire-damp from the mines of Newcastle, I conclude this account of the examination by inserting a tabular view of the composition of all the gases which have been analysed. [See Table in preceding page.]

The gas, No. 12, proved to be unmixed air. I have no remarks to offer respecting the nitrogen found in some samples of the fire-damp beyond what will readily occur to other chemists, who, I apprehend, will consider, its presence as a simple consequence of oxidizing processes, especially of metallic sulphurets, abstracting oxygen from atmospheric air.

II. Meteorological Observations during a Residence in Colombia between the Years 1820 and 1830. By Colonel Richand Wright, Governor of the Province of Loxa, Confidential Agent of the Republic of the Equator," 8 c. $\& c$.

T $F$ the materials of science could be gathered only by the 1 scientific, the following collection of observations would be a useless labour; but it frequently happens that, in distant countries, the opportunity of observing natural phænomena falls to the lot of those very ill fitted in most respects to profit by it. The genius of a Humboldt, like an incantation of science, descends upon the New World but once in a series of ages. The most that can be done by an ordinary observer is to offer his mite,-a single stone towards the pyramid of knowledge,--in the hope that he may casually prove useful; and with such humble pretensions can scarcely be deemed importunate. Should even this apology barely extenuate the sterility of a ten year's' residence in a country so admirably varied and rich in natural phænomena as Colombia, something further may be urged in excuse of the military traveller, obliged frequently to hurry through the most interesting parts, and to vegetate whole years in others of minor importance; without books, without instruments, without resources; fettered too often by the chain of his own daily wants and sufferings; and fallen on a time when every species of local and traditional information, every glimmering of philosophic research had been buried and obliterated amid the storms and struggles of the revolution.

The geographical features of Colombia have been por- 